\section{Gone to the moons}

\section{Lionel Wilson}

Satellites. Edited by Joseph A. Burns and Mildred Shapley Matthews. University of Arizona Press:1986. Pp.1,021. \$55.

LONG GONE are the days when scientists interested in the Solar System took planetary satellites to be insignificant companions of the main objects of interest. In modern planetary science it is firmly acknowledged that there is at least as much to learn about the origin and evolution of the Solar System from the study of the smaller bodies, and in particular the natural satellites, as there is from examination of the planets themselves.

Relative to the planets, the satellites exhibit a slightly wider range of sizes and a much wider range of bulk compositions. Their evolutionary histories have in most cases been influenced not only by their distances from the Sun, but also by the proximity and evolutionary history of their 'parent' planets through such processes as direct heating, tidal heating, tidal deformation and collision with other satellites or trapped cometary bodies. In particular, the availability of heat sources other than those that drive planetary thermal histories (radioactive decay and core formation), has led to evolution of satellite surfaces that might otherwise have been expected to remain in the states in which they originally accreted.

Yet the study of satellites could not go ahead without reliable and suitably highresolution observational data. As recently as the mid-1970s, only the Earth's Moon could be investigated in any great detail. This state of affairs changed dramatically with the advent first of the Viking 1 and 2 missions to Mars, which sent back images of that planet's two tiny moons, and then (and much more importantly) of the Voyager 1 and 2 missions, which have

\section{New journals review}

On 24 September Nature will publish the seventh annual review supplement devoted to science journals.

Criteria for inclusion of a journal in the 1987 issue are that:

(i) the first number appeared, or the journal was retitled, between June 1985 and May 1986 (the second cut-off date allows at least three issues of a journal to have been published, the minimum number on which a reasonable judgement can be based);

(ii) it is published at least three times a year;

(iii) the main language used is English.

Publishers and learned societies are invited to send four different issues of each suitable periodical, including the first and most recent numbers (if from outside the United Kingdom, by air mail) to: The Review Editor, Nature, 4 Little Essex Street, London WC2R 3LF, England. Subscription details for 1987 (and 1988 if possible) should be included. provided detailed information on the satellite systems of Jupiter, Saturn and, most recently, Uranus.

The timing of the reception of data from the successive Voyager fly-by events is dictated by the nature of the trajectory used to cross the Solar System, and it is inevitable that there is a gap of a few years between successive encounters. For some, these gaps have been frustrating. But one suspects they have had a positive influence on the data analysis programme that has paralleled the missions. There has been time to assimilate new data, formulate fresh models and define what observational improvements might be made at the next encounter; graduate students associated with one phase of the mission have become junior team members by the next; and there has been a continuity of attention from the theoreticians which has itself been an important factor in the advance of many aspects of the research.

\section{Floristic features}

\section{Peter D. Moore}

The Savannas: Biogeography and Geobotany. By Monica M. Cole. Academic: 1986. Pp. 438. \$79.50, £46.

SAVANNA covers 20 per cent of the Earth's land surface, and provides a resource for vast numbers of domestic animals and wildlife. It is therefore a biome worthy of note. But controversy surrounds the definition, classification, mode of origin and maintenance of these tropical grasslands and parklands. All studies on their value as natural resources hang upon a commonly accepted terminology and use of vocabulary, and it is one of Monica Cole's aims to provide that framework.

She begins with definitions and generalities, and then moves on to detailed accounts of the savanna vegetation of South America, Africa, India, South-East Asia and Australia. The most distinctive feature of these descriptions is the concentration upon floristic features rather than on the ecosystem as a whole. Little is said about primary production, patterns of energy flow or nutrient cycles, but the vegetation is described in impressive geographical and botanical detail. This says much for the wide field experience of the author, and it puts her in an authoritative position to advance the definitions proposed at the beginning of the book.

In addition to the descriptive material, Cole puts forward some strongly held views on the environmental determinants of savanna. Much speculation surrounds this subject, mainly centred on the relative roles of climate, soils and man (including the grazing of stock and the use of fire) in bringing the savannas into being
All of these subtleties are in evidence in this excellent set of review and discussion papers, the latest in a long series of such volumes fostered by the University of Arizona. Based on a conference held in 1983, the contents nevertheless run up to late 1985 (and early 1986 for the Uranus encounter). Particularly striking is the range of coverage, from the origins, internal structures and evolutionary histories of the satellites, through their present surface states, to their interactions with one another, their parent planets and the interplanetary environment. This collection will be essential reading for all students of the Solar System. It will also do much to make the wider scientific community aware of the exciting state of planetary research.

Lionel Wilson is a Senior Lecturer in the Department of Environmental Science, University of Lancaster, Lancaster LA1 $4 Y Q, U K$, and a Professor at the Hawaii Institute of Geophysics.

and maintaining them in their relatively open state. In the past there has been emphasis upon the sharp boundaries that often exist between savanna and forest, leading to the conclusion that fire is the primary causative factor in the maintenance of savanna. Cole, by contrast, stresses the importance of geomorphological and climatic factors. Her attitude can be summarized by her comment about West Africa: "notwithstanding the importance of fire, vegetation distributions including those of forest and savanna and of different categories of savanna are controlled by interacting physical factors upon which fire and man's cultural practices impose a secondary influence".

Savanna occurs in regions with summer rain and winter drought. Where the water supply and moisture retention in the soil is inadequate to support forest, savanna develops. Grazing, according to Cole, may be disregarded as a primary determinant, because savanna is found both in continents with rich herbivorous faunas, such as Africa, and poor ones, such as Australia. Such influences may have affected the evolution of spiny forms of growth, but not the general physiognomy of the savannas.

Cole's position on savanna development is argued throughout the book with conviction and with abundant local illustrations. She presents a strong case, but one detects an element of partisan spirit perhaps even bias - in her complete neglect of the human factor in her diagrammatic model of savanna-environment relationships. This comes in the opening chapter, and is a disturbing introduction to a book which is far more balanced than the diagram may lead one to expect.

Peter D. Moore is in the Department of Biology, Kings College London $(K O C)$, Campden Hill Road, London W8 7 AH, UK. 